A Journal for Language Learning Tydskrif vir Taalaanleer

\title{
AN OVERVIEW OF THE ZHEJIANG MODEL OF TEACHER TRAINING
}

\author{
Dan-Dan Zheng, Yabing Gao \& Chao Wang \\ Zhejiang International Studies University, China
}

The quality of teacher training directly affects the quality of primary and secondary school teachers' professional development and indirectly affects the quality of primary and secondary school education. With an interest in teacher development, this paper presents an overview of the Zhejiang model of teacher training, with specific reference to the training of Chinese language teachers. This paper analyses the guidance of government's teacher training policy, the design of training programmes, the qualifications for teacher-training institutions, the composition of trainer teams, the improvement of training management, financial support of teacher training programmes and the change of the organisational mode of teacher training programmes. Through examining the case of the training programme for Chinese language teachers, it was found that current teacher training practice in Zhejiang Province aims to follow the country's education reform policy. Teachers are allowed to make their choices about which training programmes to attend. All the training institutions are open to competition. The improvement of the quality assurance mechanism is the guarantee for the success of the practices of free choices of teachers and free competition of institutions.

Keywords: teacher training; training programme; Zhejiang model

\section{INTRODUCTION}

An important factor affecting the quality of primary and secondary school education is the quality and development of primary and secondary school teachers, which in turn depends on the development of teacher education and training. Under the auspices of lifelong learning, teacher training methods in China have in recent years had an impact on the development of teacher education and teaching quality (Ma, 2012:32), but the methods used in the field of education must still undergo constant improvement.

Economic shifts also have implications for the needs of education ${ }^{1}$. Since 2004, Zhejiang province has taken the lead in providing 15 years of school education to all, which spans preschool to high school. The enrolment rate for a 15-year school education in the province has reached 98.4\%. From the Zhejiang Province Medium and Long-Term Education Reform and Development Plan (2010-2020), it seems that Zhejiang education on the whole is playing an active role in enriching the meaning of 'quality education'. This enrichment comes from paying attention to the quality of primary and secondary school education.

As a result of an improvement in the quality of primary and secondary school education, it

\footnotetext{
${ }^{1}$ Zhejiang is a relatively developed province on China's south-eastern coast in terms of economic strength and vitality. Since 2012 the province's GDP has shown an average growth rate of $9.6 \%$ in the past five years, and an increase of $8 \%$ compared with the same period last year. It is believed that the type of economy of Zhejiang Province has already been changed from an industrial economy to a post-industrial economy, with the share of service industry in GDP almost raised to the level of a manufacturing industry.
} 
has become the focus of education reform, thus quality schooling will be reflected in educational research. The education profile in Zhejiang Province in 2013 shows that in the early stages of education in the province, which includes kindergarten, elementary school, secondary school, special education, and secondary vocational education ${ }^{2}$, there are 598443 teachers altogether, including 478693 ?? who work full time. According to the requirements of the country and province, these teachers must take part in in-service training.

With regard to teacher training, the Ministry of Education enacted the Ministry of Education's Advisory on Vigorously Strengthening Primary and Secondary School Teacher Training on 4 January 2011. Among all those new requirements for teacher training listed in this document, the relevance and effectiveness of training content is highlighted. All institutes providing teacher training services are expected to conduct research on teachers' real demands in their professional development. The overall standard of teacher training set out in this document is higher than previous national standards. Since 2010, three policy documents have been issued: Several Provisions on the Primary and Secondary School Teachers' Professional Development Training in Zhejiang Province (Trial) was issued on 7 December 2010; the Measure of Verifying Primary and Secondary School Teacher Training Institutions in Zhejiang Province (trial) was issued on 16 July 2011; and the Guidelines on the Design of Primary and Secondary School Teachers' Professional Development Training programmes in Zhejiang Province was issued on 19 November 2011, in Zhejiang Province. These three policy documents laid the foundation for and shaped a unique model of teacher training in Zhejiang Province.

In its review ambit, this paper considers policy documents from both provincial and central government, as well as academic research to outline current teacher training practices in Zhejiang Province. Thereafter it focuses specifically on the policy and practice of The National Training Plan and the Training programme of Backbone Chinese Teachers in Primary School in Zhejiang Province. The latter two cases show how the implementation of the teacher training model in Zhejiang Province went from policies issued by the government to concrete practice, and from this process we can explore the Zhejiang model more closely, especially with reference to language teaching.

\section{ZHEJIANG MODEL OF TEACHER TRAINING}

In this section we look at factors that underpin successful teacher development programmes. These include the implementation of policy, the content of training programmes, qualifications for teacher training institutions and so on.

\footnotetext{
${ }^{2}$ Kindergarten is for 3-6 year old students. Elementary school is for 6-12 year old students. Secondary school includes both junior and senior high school and it is for 12-18 year old students. Special education caters for students with special needs, physically and/or mentally, and is provided through special elementary schools and special secondary schools. Secondary vocational education takes the form of vocational high schools, secondary specialised schools, adult secondary specialised schools and technical schools. Secondary specialised schools, which are gradually phasing out, are more vocational-oriented than vocational high schools, and the graduates from the latter are still allowed to apply for certain kinds of university programmes with a vocational orientation.
} 


\section{Overview of teacher training policy}

Teacher training in Zhejiang Province is regulated by government policy. A series of policy documents in support of teacher training set out the general requirements regarding teacher training. The Outlines of Education Modernization in Zhejiang Province (2000-2020) deals with policy regarding the make-up of a high-quality teaching staff. The Zhejiang Province Medium and Long-Term Education Reform and Development Plan (2010-2020) relates to the improvement of the teacher training system and strengthening the teacher training base.

Since the beginning of the 21 st century, national quality standards for primary and secondary school teachers such as teacher qualification systems and teacher registration systems have been established (Chai, 2014: 1). In 2011, Zhejiang, as a pilot project, carried out a national pre-service teacher qualification examination reform plan and an in-service standardised teacher registration system (The Office of Education in Zhejiang, 2011: 1). An access and exit mechanism was also established for the teaching profession. In 2013, provincial government introduced a headmaster and teacher exchange programme into the public school system (The Office of Education in Zhejiang, 2013:1). In this programme, every year, public schools are required to exchange a certain number of headmasters and teachers with each other for a period of three years in order to address the imbalance in teacher development in public primary and secondary schools in different neighbourhoods. The proportion of headmasters and teachers to be exchanged for a particular year is stipulated by the government. For example, in the second half of 2014 in Hangzhou, which is the provincial capital of Zhejiang Province, 1409 teachers moved between schools, including 305 'backbone teachers' and 177 principals. Backbone teachers are those with a high professional level and who have been rewarded many times for their outstanding performance in the teaching profession.

Recently the number of teachers holding higher degrees, i.e. a bachelor, masters, or doctoral degree, has greatly increased in Zhejiang Province. For example, Zhejiang Normal University now offers postgraduate degree education for primary and secondary teachers (Xue, 2006: 19). However, an academic degree does not guarantee quality teaching. What needs to be further observed is the long-term development of teaching staff and determining what role teacher training plays in their career. Zhejiang Province is now actively promoting reform in the primary and secondary school teacher training system. It is said that Zhejiang Province ignited the Teacher Training System Reform (Bao \& Pan, 2011: 4). It seeks to highlight teachers' independent selection of training programmes and encourages competition between training institutions. In the interests of effectiveness in teacher training, the province has also taken responsibility for the formulation and implementation of primary and secondary school teachers' professional development training.

On 7 December 2010, another policy document, Several Provisions on the Primary and Secondary School Teachers' Professional Development Training in Zhejiang Province (Trial), was issued in Zhejiang Province, which required setting up the Provincial Steering Committee for teacher professional development. This committee is now responsible for the preparation of the Teachers' Professional Development Training Guide. In this guide, the specified training cycle for primary and secondary school teacher professional development is five years. Every five years, primary and secondary school teachers are expected to 
participate in at least 360 hours of professional development training, of which school-based training time is at least a third of the total training time. The training can be conducted both in centralised and decentralised ways. This means that teachers can either take leave from their schools to attend training programmes in other venues for several days with other teachers, or else carry out self-studies without leaving their teaching posts in their schools. If a teacher leaves for a training programme, considering the resources available, the headmaster will decide whether the teacher should make up the lessons missed due to the off-the-job training after he/she returns or a substitute teacher shall be appointed to fill the gap. Sometimes, a student teacher will be tasked to teach as a substitute under certain circumstances. In some schools, there will be senior student teachers who are part of teacher education programmes, and who are required to do teaching practices every year, available. Every year, all teachers are acquired to finish at least 24 hours of training. In one training cycle, teachers should attend at least 90 hours of training. New teachers with less than one year of training experience are required to complete at least 180 hours of training - including at least 60 training hours of practical training. It should be noted that training during the first year is not counted in the five-year training cycle of teacher professional development.

\section{The content of training programmes}

One of the most salient characteristics of current teacher training can be summarised in one word: new. Training content needs to include new theories, new technologies and new methods. Many teachers who need in-service teacher training have been in the teaching profession for a long time and are not familiar with new trends. Teacher training thus needs to incorporate new knowledge to train teachers on new educational reforms (Zhang \& Ying 2013: 4)

On 19 November 2011, a policy document relating to the content of teacher training was issued, the Guidelines on the Design of Primary and Secondary School Teachers' Professional Development Training Programmes in Zhejiang Province. This document was more practice oriented. It aimed at training high quality teaching staff and improving teachers' ethical accomplishments and competence. It also proposed further requirements for training programmes. The document stated that the current teacher training programmes should be mainly designed around two key ideas, viz. teacher requirements and thematic design of the training sessions. From the different ideas put forward for teacher professional development, it appears that different training programmes were designed for different teachers. In addition, there were also several special projects aimed at rural teachers. Each project had a central theme.

It is important to first grasp several basic pedagogical components which are required for teacher training programmes both at national and provincial level, such as professional ethics, professional knowledge, professional skills, and so on (Ministry of Education and the Ministry of Finance in China, 2010: 1; The Office of Education in Zhejiang. 2008: 1). In teacher training programmes, the project content can normally be divided into three parts: teachers' professional ethics, teachers' professional knowledge, and teaching skills. With regard to the training of teachers' professional ethics, there are three training modules including the teachers' professional moral standard, the teachers' professional consciousness and the teachers' comprehensive quality. The training of professional knowledge comprises four training modules including background knowledge, basic theory of education, education 
psychology and discipline knowledge. For the training of teaching skills, there are five training modules including classroom teaching, education management, interpersonal communication, modern education technology, and education research.

\section{Qualifications for teacher training institutions}

Since the mid-1990s, the teacher education system in China has gradually changed from a closed system to a relatively open system. For quite some time, only those normal universities and normal colleges which are dedicated to teacher education were allowed to offer teacher training programmes. But nowadays, many comprehensive universities are also participating in training teachers as there are also schools of education established in those universities and facilities are installed for the purpose.

The most important requirement of teacher training institutions is that each should have specialised and varied characteristics when implementing teacher training programmes. However, determining which colleges and universities should be involved in teacher training is now decided by which institutions hold specific qualification certifications. On 16 July 2011, the Measure of Qualification of Primary and Secondary School Teacher Training Institutions in Zhejiang Province (Trial) were issued which provided specific criteria for being established as teacher training institutions. This document, based on the open system of teacher training, highlighted the competition between teacher training institutions. Its aim was to require teacher training programmes to share resources in the interest of high-quality teacher training. The direction of teacher training reform comes from the original marketing strategy of regional segmentation, to open up and introduce more competition into the system. Training institutions can develop training programmes for different provinces, cities, and even at a national or district level. This kind of variation allows individual teachers to choose different projects according to their own specific needs.

Teacher training institutions first need to obtain their qualification authentication by accepting supervision and guidance in the training process and undergoing regular evaluation by the province (Ministry of Education in China, 2011: 2; The Office of Education in Zhejiang. 2011: 3). Current qualifications for teacher training institutions in Zhejiang Province are valid for three years. Training institutions wishing to continue offering teacher training courses have to apply for an evaluation from the Education Administration Department of Zhejiang Province as their qualification expiry date approaches. Training teams within these institutions are responsible for in-service teacher development programmes.

\section{The composition of training teams}

In order to guarantee the quality of teacher training institutions, attention should be paid to the composition of training teams. The training teams at teacher training institutions comprise mainly college and university teachers. In the past, teacher training was criticised for having too many teachers from higher education institutions, with an over reliance on teaching theory (Zhang \& Ying, 2013: 4). In recent years both national and local projects have changed policy on the composition of training staff. For example, the focal point of the 'National Primary and Secondary School Teacher Training Programme' (National Training Plan) in 2013 is said to 'further strengthen outstanding teachers and teaching-research staff 
who account for no less than $50 \%$ in the proportion of trainer teams in training programmes' ?(Ministry of Education and Ministry of Finance 2013: 1). In other words, in addition to university teachers, teacher training should also include highly successful and well-known primary and secondary school teachers or possibly teaching-research staff. They should also employ technical personnel and persons with other skills who have practical experience as part-time trainers in teacher training programmes. This also formed the beginning of a dualbased and dual-tutorial system, which means dual practice in colleges and universities, as well as in primary and secondary schools. This also allows for dual guidance from highereducation experts as well as well-known primary or secondary school teachers.

\section{Standardising project management}

The success of teacher development programmes relies on its management. Teacher training in Zhejiang Province is uniformly managed by the education department at all levels. For the management of teacher training institutions, in the interest of quality assurance in programme management, a teacher-education quality monitoring centre was set up at Zhejiang Normal University on 5 August 2014. The result of this is that the primary and secondary school teacher training and professional development training programmes in Zhejiang Province have specialised agencies responsible for quality monitoring. In future, the centre will perform functions such as checking and supervising teacher-education quality management, monitoring the primary and secondary school teacher training implementation process, occasionally inspecting and assessing teacher education, publishing annual reports on teacher-education quality monitoring, and guiding teacher training institutions' management on the quality of teacher education. Each year this centre will compile a compendium regarding teacher professional development. This will include an annual performance evaluation index of teachers, assessment results, essential conditions of employment, recruitment, promotion, appraisal, and awards bestowed on teachers. The assessment of teachers by training institutions occurs during and after project implementation.

With regard to the management of teachers, schools are obliged to list the professional development training of teachers as the annual performance evaluation index of teachers, and take the assessment results into consideration in the conditions of employment, recruitment, promotion, appraisal of and awards to teachers. As previously mentioned, the training institutions assess the teachers in training during and after the project implementation.

\section{Financial support of teacher training}

The responsibility for the financial support for teacher training falls on municipality and county (city or area) government. In Zhejiang Province, local money is arranged into special funds to support primary and secondary school teacher training activities respectively (The Office of Education in Zhejiang 2012: 1); each year these funds comprise no less than 3\% of the total wages of local teachers. Primary and secondary schools are expected to set aside these special funds for the purpose of teacher training only. These funds should be no less than $10 \%$ of schools' annual allocation for public daily expenses.

Every year at provincial level, the government arranges for special funds to subsidise provincial training programmes. 


\section{Changes to the organisational mode of teacher training programmes}

Organisation of the programmes is also very important for the effective implementation of teacher trainings. The organisational structure of teacher training programmes has also undergone changes. In the first five years of the training cycle, the organisation of teacher training in Zhejiang should change from being driven by administrative demands to being driven by the independent choices of teachers. This means that the Zhejiang model will change from a top-down arrangement into a bottom-up, market-oriented choice. To facilitate adaptation to these changes, all the teacher training information is to be put into the teacher training curriculum management platform via a computerised network (Zhu, 2011: 1). This application will enable one to review the distribution of teacher training programmes, teachers' selection of training programmes, auditing, special groups, notifications and grade input.

Teacher training institutions are expected to focus on designing projects that will attract teachers' interests. Before organising training programmes, teacher training institutions should contact primary and secondary school teachers in order to investigate and analyse the different needs of teachers and then use this information to design various training modules for trainees. By carefully choosing the training content, training institutions can design projects that combine the demands of national standards of teachers with the professional development needs of different teachers (Feng 2012: 65). It is therefore important for the design of training programmes to be both useful to the teachers undergoing training and to meet the national standards required of teachers.

From the teachers' perspective, they will be able to choose training programmes according to their own professional development needs. All information relating to training can be accessed through the teacher training curriculum management platform. Just by logging onto the application on the internet, teachers can complete a series of operations including training programmes selection and viewing their final project evaluation. On the platform, teachers can also browse through the training introduction to see whether the design and arrangement of a project are likely to meet their needs.

If teacher training institutions want to attract teachers to engage in their training programmes, they must win them over by guaranteeing the relevance and quality of their own training designs. Currently, both teachers and training institutions are paying more attention to the combination of theory and practice.

Additionally, the needs of rural primary and secondary school teachers have been one of the priorities of teacher training in Zhejiang Province in recent years. Besides regular teacher training, the government has also organised special training for rural primary and secondary school teachers. From 2005 to 2007, a Quality Promotional Project for all rural teachers was carried out in Zhejiang Province. The number of rural teachers who received training at this event numbered more than 180 000. From 2008 to 2010, the 'Leading Wild Geese' project was implemented (The Office of Education in Zhejiang, 2008: 1). This project aimed at training excellent rural teachers who were seen as the 'Wild Geese' leading other rural teachers. This project trained more than 39000 teachers in rural areas. These projects 
effectively improved teachers' teaching ability and teaching quality (Xiang, 2011: 163). Special rewards were also set up for rural teachers in Zhejiang Province. For example, in 2009 the provincial government established the Outstanding Contribution Award for Rural Teachers of the Province, which, once every two years, honoured those who made outstanding contributions to rural education. To date, 300 rural primary and secondary school teachers have received this honorary title.

We turn our attention now to Chinese language teachers and the specific requirements needed to teach this subject.

\section{TRAINING FOR CHINESE LANGUAGE TEACHERS}

To become a Chinese language teacher in primary schools in China, one is expected to participate in pre-service teacher training programmes, take courses related to linguistics, pragmatics, literature reading, philology and literacy teaching, pedagogy of teaching Chinese in primary schools, study state-released curriculum standards for Chinese language teaching in primary schools, textbooks, and so on, and participate in teaching practices. Besides, passing the national teachers' qualifications exam for primary schools and reaching the top level of second grade of standard Chinese language proficiency in speaking ('Putonghua shuiping kaoshi' in Chinese) ${ }^{3}$ is a must for teaching Chinese in primary schools. As for teachers teaching subjects other than Chinese language, a basic level of second grade of standard Chinese language proficiency in speaking will be sufficient. Once teachers get into the profession of teaching Chinese in primary schools, continuous in-service training is required throughout their professional life. Traditionally, in-service training programmes tend to focus more on introducing new ${ }^{4}$ teaching theories, but now more and more attention is paid to the actual needs of the teachers and to try to inspire them to solve the problems and address the challenges in their daily work. Several characteristics of the Zhejiang model of teacher training could be revealed through the examining of the following case and it is a training programme for Chinese language teachers in primary schools.

In the Training programs of Backbone Chinese Language Teachers in Primary Schools in Zhejiang Province, the participants are those with the potential and the desire to be the 'Leading Wild Geese' in Chinese language teaching in their respective schools. The main theme of this project is to help them further develop their own teaching abilities and skills in Chinese language teaching in primary schools and prepare them to take a leading role in their domain.

Each language project is made up of several training modules related to Chinese curriculum standards, primary school Chinese teachers' language awareness, phonics and vocabulary teaching in primary school, and teaching skills and strategies for Chinese writing. Among all those modules, 'phonics' is very important, because it is the foundation for learning Chinese characters and it is an important content required by the curriculum for Chinese language learning in primary schools (Zhong, 2013: 63).

\footnotetext{
${ }^{3}$ The top level of the first grade of standard Chinese language proficiency in speaking is required for the profession of broadcaster, and the basic level of the first grade of standard Chinese language proficiency in speaking is the precondition for being a tester for the Test of the Standard Chinese Language Proficiency in Speaking. The test is mainly for domestic people and it has nothing to do with the HSK (Hanyu Shuiping Kaoshi)

${ }^{4}$ Theories may not be that new, but they are new to the teachers in the field or easily being ignored by the teachers.
} 
Each module is developed around four pillars: ethics, teaching research, Chinese language teaching research, and the ability to take leadership in teacher professional development in their respective schools. Because the purpose of this in-service training is to cultivate disciplined leaders, the focus is always on core skills relevant to language teaching, such as text reading skills, lesson planning design and classroom management. In classroom management, for example, the training includes several activities:

- Theory and strategy of classroom management

- Micro-teaching of classroom management

- Personal strengths and weaknesses in classroom management

- Research activities: Participants share their demonstration lessons with peers and trainers, and discover their own teaching style through discussions.

As for the training for improving reading instruction, the four main training content areas are studies on the three-dimentional objective, appropriate selection of reading materials/portion of reading materials to teach, the ability to identify core competences in reading, and the ability to do diagnostic assessment in reading instruction. The three dimensions of the threedimensional objective are (1) knowledge and skills, (2) process and steps and (3) emotion, attitude and values. Trainees should comprehend the meaning of such concepts and know how to integrate these in reading instruction. Given the vast array of reading material available, teachers should know how to select suitable material appropriate for the grade level of their students. For example, teachers may compare alternative materials with the material in the text book, and decide which will be used in actual teaching. Teachers should also learn to identify the core competencies that will make a difference in students' reading development. Diagnostic skills involve the ability to make use of some scales and questionnaires to check the outcome of reading instruction and make a self-check for teachers' performance in teaching.

The training method for classroom management combines theory, practice, self-reflection and integrated practice. Such training not only requires theoretical study but also highlights the self-reflection and research ability of a leading teacher in the field of Chinese language teaching.

The Training programmes of Backbone Chinese Language Teachers in Primary Schools in Zhejiang Province applied the 'Dual-based system' and 'Dual-tutorial system'. Each trainee is assigned a theoretical mentor and a practice mentor to guide them through the theoretical and practical sections respectively. Each programme lasts 30 days or 180 hours of training, including 90 hours of theoretical study and 90 hours of practical training. The trainer team for this programme is made up of six professors from colleges and universities, 17 top-level teachers from primary and secondary schools, and 11 researchers.

To guarantee the quality and effectiveness of the training programme, all participants should complete the following assignments:

- 1 personal/professional development plan assignment

- 1-2 copies of descriptions about key events which have a major impact on their personal professional development 
- 3 copies of teaching narratives

- 4 copies of reflections on their teaching performances, i.e. teaching design, and effectiveness of their teaching

- 3 personal lesson plans

- 2 reports around certain teaching themes

- 1 written essay on a specific theme (more than 5000 words)

- 1 public class teaching session or seminar.

Various training methods are applied in the Training programmes of Backbone Chinese Language Teachers in Primary Schools. Top-level teachers' studio interviews, personal blogs, lessons, lectures and research activities are among the most popular. When it comes to the teacher trainee, debates (aimed at making trainees more competent at verbal persuasion), essay writing, report study, teaching practices, and extra activities such as practice teaching in rural schools are all involved. Diverse activities are widely welcomed by the participants.

\section{The efficacy of the Chinese language training programme}

The success of any reform in teacher training policies relies on how it is implemented, and shall be measured by professional development of teachers who are involved. As for the above-mentioned training programme, upon completion, participant teachers are invited to leave their comment about the effectiveness of the programme on an appropriative online platform for collecting feedback for the training programmes. Many teachers reported that the programme had changed their teaching ideas and behaviours in many aspects. In the past, they used to follow the teacher-centred way of teaching, but now they tend to pay more attention to the three-dimentional objective and the cooperation and interaction with students. In the past, knowledge flowed in one way in class, i.e. from teacher to students, but now it flows in many different ways. The teachers reported that they have learned to appreciate students' own solutions to challenges, and there are more information exchanges among teachers and students. In terms of the change in students' learning style, less passive acceptance and more autonomous and cooperative learning are encouraged. Inquiry approaches are used more frequently than before. However, the instalment of a self-report mechanism is far from sufficient for measuring the success of a teacher training programme. Follow-up studies, including classroom observations and comparisons of students' performance before and after their teachers participated in training programmes, will provide us with more reliable information about the success and problems of teacher training programmes. However, those follow-up studies have not yet started.

Following the initial effects of Chinese teacher training, we put forward some recommendations based on outstanding features/characteristics of the Zhejiang model of teacher training.

\section{REFLECTIONS}

On examining the Zhejiang model of teacher training and the teacher training programme for Chinese language teachers in primary schools, the following two aspects are worth discussing. 


\section{More choices and more open competitions among different providers}

Traditionally, teacher training was fashioned in the similar way as a doctor prescribing medicine to a patient. Previously, teachers did not make any choices. But now, with the support of relatively abundant education and training resources mobilised in Zhejiang Province, more and more choices are available for teachers to choose from. It is compulsory for teachers to participate in training programmes, but they are now given more choices on when, how, where and what to learn. Training providers are now trying to develop various programmes to cater for the diversified needs of teachers. The change is already beginning, and will continue.

The benefit of this change is obvious, allowing teachers more choices which will stimulate their intrinsic motivation towards personal professional development, that is, their concept of training will change from 'You want me to learn' to 'I want to learn for myself'. Teachers must still complete certain training credits within a certain period, but the programmes they are attending can be decided by themselves.

As for training providers, the change brings the challenge of improving the quality and relevance of their programmes so as to attract more participants. Further standardisation of the management of teacher training providers would help in this endeavour. As is required by new policies, all training providers should be certified and this will encourage local government to pay more attention to the operation of training providers funded by its money, and will encourage it to increase investment in those well-performing ones. As for those providers who are not up to standard, it is time for them to consider the way forward and decide how to adapt to the changing market.

\section{A more reliable quality assurance system is needed}

The key to ensuring the quality of teacher training programmes lies in the quality of the teams of trainers.

On 4 January 2011, Advice on Vigorously Strengthening Primary and Secondary School Teacher Training Work by the Ministry of Education was issued. This policy put forward a plan to develop the trainer teams for training programmes. Trainers can work on a full-time or part-time basis, and more high-level experts and model teachers drawn from primary and secondary schools are expected to be recruited as part-time trainers. Those part-time experts and model teachers will bring with them their rich theoretical knowledge and abundant practical experiences, however, their lack of sense of identity in the trainer's team might be a big challenge due to the part-time nature of their services (Sun 2012: 43).

Recruiting qualified trainers is important, and how to make those recruited trainers' work more effective is also very important. The authorities are now focusing on improving the evaluation system for trainers and creating a dynamic management mechanism for trainer teams. Teacher trainers themselves are now required to participate in training programmes designed for them and they are expected to participate in such programmes at least 72 hours per year. However, the stability and upgrading of the quality of existing trainer teams remains a matter which requires some more attention. 
When talking about quality assurance of teacher training programmes, more attention should be paid to tracking the long-term effects. The immediate effectiveness of the programmes is already being checked through a participant self-reporting mechanism. In Zhejiang Province, an online platform has already been established for collecting participants' comment about the programmes and self-reporting on what they have learned and the changes in their thinking immediately after attending the programmes. But when it comes to the actual influence on their teaching behaviours, their future professional development, and the actual influence of the changing of teaching behaviours on the performance of their students, it remains a mystery. Hence, establishing a fully-fledged long-term tracking system for participants' future professional developments and the improvement of their students' performance seems to be the necessary next step for improving the quality assurance system and those important feedbacks will provide the training providers with more reliable evidence for further improvement of their training programmes.

Without a long-term tracking system in place, however, there is still some way for the providers to checkmonitor? the long-term effects of their programmes indirectly, although it is not sufficient enough.

As in the case of the training programme for Chinese language teachers, participants report that it has greatly changed their way of teaching and they have witnessed rapid development of their students in language learning since the change in the way of teaching. Besides, all kinds of honours they have gained in teaching skills competitions and 'academic books (mostly personal experience based)' they have published, will reflect the effectiveness of the trainings they have participated in indirectly. However, there is no solid evidence about what they have reported abouton? the improvement of their students' performance.

The change of the regulatory policy of teachers' qualification will provide some help in building a long-term tracking system. On 15 August 2013, the Ministry of Education issued the Interim Measures for Primary and Secondary School Teachers' Qualification Registration on a Regular Basis. According to this policy, primary and secondary school teachers' qualifications shall be renewed every five years. For this purpose, teachers shall be evaluated regularly (at least every five years) in three aspects, the abidance by the teachers' code of morality, annual performance in teaching profession, and active involvement in in-service training. This policy will be implemented in Zhejiang Province as a pilot, but there are still several years ahead before the first batch of teachers' qualifications reaches their review date. Hence, it is still too early to say what could be done by then.

However, it will be no easy task building a long-term tracking system. Personnel, financial support, a clear policy framework, information systems, etc. all might present possible hurdles and it will require the joint efforts from education authorities at different levels, training providers, schools and any other institutions where teachers work.

\section{REFERENCES}

BAO, FC \& JK Pan. 2011. Zhejiang Province Ignite the Teacher Training System Reform. Guangming Daily, 2011-12-18 (4).

CHAI, W. 2014. Basement and Source of Education: An Overview of the Achievements of Teacher Team Construction in China in Recent 30 Years. China Education Daily, 20149-3(1). Available from http://paper.jyb.cn/zgjyb/html/2014-09/03/node 2.htm. 
[Accessed: 15 November 2014]

FENG, GR. 2012. Teacher Training Strategies under the Background of the National Training Plan. Journal of Jivaro Normal College, (1): 63-65.

MA, XY. 2012. Review of Research about Teacher Training Model over the Last Decade. Journal of Beijing Institute of Education, (4): 32-36.

MINISTRY OF EDUCATION IN CHINA. 2011. The Ministry of Education's Advice on Vigorously Strengthening Primary and Secondary School Teacher Training Work. Available from http://www.moe.gov.cn/publicfiles/business/htmlfiles/moe/s7034/201212/xxgk_146073 .html. [Accessed: 5 March 2014].

MINISTRY OF EDUCATION AND MINISTRY OF FINANCE IN CHINA. 2013. The Notice on the Implementation of 'the National Training Plan' by the Ministry of Education and the Ministry of Finance. Available from http://www.moe.gov.cn/publicfiles/business/htmlfiles/moe/s7525/201304/150803.html. [Accessed: 5 March 2014].

MINISTRY OF EDUCATION AND THE MINISTRY OF FINANCE IN CHINA. 2010. The Notice on the Implementation of 'The National Training for Primary and Secondary School Teachers' by the Ministry of Education and the Ministry of Finance. Available from http://www.gov.cn/zwgk/2010-06/30/content_1642031.htm. [Accessed: 5 March 2014].

MINISTRY OF EDUCATION IN CHINA. 2013. Interim Measures for Primary and Secondary School Teachers' Qualification Registration on a Regular Basis. Available from

http://www.moe.gov.cn/publicfiles/business/htmlfiles/moe/s7085/201309/xxgk_156643 .html. [Accessed: 5 March 2014].

SUN, Y. 2012. The National Training Plan is Beyond History and Has Realistic Obstacles, Education Theory and Practice, 33(22): 41-44.

THE OFFICE OF EDUCATION IN ZHEJIANG. 2000. The Outlines of Education Modernization in Zhejiang Province (2000-2020). Available from http://www.zjedu.gov.cn/gb/articles/2005-05-08/news20050508160238.html. [Accessed: 6 March 2014].

THE OFFICE OF EDUCATION IN ZHEJIANG. 2008. Zhejiang Province is Planning to Implement the 'Leading Wild Geese' Project for Rural Primary and Secondary School Teachers in Three Years Which is Aiming to Train 33000 Backbone Teachers. Available from http://www.zjedu.gov.cn/news/11560.html. [Accessed: 6 March 2014].

THE OFFICE OF EDUCATION IN ZHEJIANG. 2010. Several Provisions on the Primary and Secondary School Teachers' Professional Development Training in Zhejiang Province (trial). Available from http://www.zjedu.gov.cn/gb/articles/2010-1209/news20101209175655.html. [Accessed: 6 March 2014].

THE OFFICE OF EDUCATION IN ZHEJIANG. 2010. Zhejiang Province Medium and Long-Term Education Reform and Development Plan (2010-2020). Available from http://www.zjedu.gov.cn/gb/articles/2010-12-24/news20101224163919.html [Accessed: 6 March 2014].

THE OFFICE OF EDUCATION IN ZHEJIANG. 2011. The Notice on Adjustment in the Second Half of 2011 about Teachers Qualification Test by the Office of Education in Zhejiang. Available from http://www.zjedu.gov.cn/news/18980.html. [Accessed: 6 March 2014].

THE OFFICE OF EDUCATION IN ZHEJIANG. 2011. The Measure of Verifying Primary 
and Secondary School Teacher Training Institutions in Zhejiang Province (trial). Available from http://www.zj.gov.cn/art/2012/2/14/art_12880_41939.html. [Accessed: 6 March 2014].

THE OFFICE OF EDUCATION IN ZHEJIANG. 2011. The Guidelines on the Design of Primary and Secondary School Teachers' Professional Development Training Programmes in Zhejiang Province. Available from http://www.zjedu.gov.cn/gb/articles/2011-11-25/news20111125140349.html. [Accessed: 6 March 2014].

THE OFFICE OF EDUCATION IN ZHEJIANG. 2012. The Notice on the Evaluation Standards of Education Modification in the County, City and District. Available from http://www.zjedu.gov.cn/news/21095.html. [Accessed: 6 March 2014].

THE OFFICE OF EDUCATION IN ZHEJIANG. 2013. Building the Principals and Teachers Communication System between Public Compulsory Schools in Zhejiang. Available from http://www.zjedu.gov.cn/news/24132.html. [Accessed: 6 March 2014].

WANG, C. 2014. Training programme of Backbone Chinese Teachers in Primary School in Zhejiang Province. Hangzhou: The Office of Education in Zhejiang.

XIANG, RR. 2011. Research on Regional Characteristic of 'Leading Wild Geese' Project of Teachers of Junior and Primary Schools in Rural Area. The Guide of Science \& Education. (11): 95,163.

XUE H. 2006. Implement Distinct Teachers Education to Promote the Construction of Education in Zhejiang Province. Journal of National Academy of Education Administration, (3): 18-23.

ZHANG, GF \& B YING. 2013. Research on Admittance and Evaluation Mechanism of Professional Continuing Education Faculty under the Background of Classification Management in Zhejiang University. Continuing Education, (7): 3-6.

ZHONG, WL. 2013. Improve the Teaching of Chinese Phonics Teaching in Primary School. Basic Education Research, (4): 63.

ZHU, ZY. 2011. Independent Choices of Training Programmes by Primary and Secondary Teachers. China Education Daily, 2011-7-13(1). Available from http://paper.jyb.cn/zgjyb/html/2011-07/13/node_2.htm. [Accessed: 15 November 2014].

\section{BIOGRAPHICAL NOTES}

Dan-dan Zheng is a lecturer at the School of Educational Science at Zhejiang International Studies University, China. Her main research interests include teacher education, comparative education, curriculum and teaching theory. E-mail: zddzhengdandan@163.com

Ya-bing Gao is a professor at the School of Educational Science at Zhejiang International Studies University, China. Her main research interests include psychological development of children and teenagers, and school psychological consultation. E-mail: gyb@zisu.edu.cn

Chao Wang is a professor at the Teachers' Training Institute at Zhejiang International Studies University, China. His main research interests include curriculum and teaching theory for Chinese language teaching in primary schools. E-mail: wangchao622434@sina.com 